\title{
Financial Support for Small and Medium-Sized Enterprises in China Amid COVID-19
}

\author{
a,b Shanghai University of Finance and Economics, Shanghai, China; \\ ' National Center for SCO - Shanghai University of Political Science and Law, Shanghai, China \\ ${ }^{a}$ https://orcid.org/0000-0003-4049-5418; ${ }^{b}$ https://orcid.org/0000-0001-8719-663X; \\ chttps://orcid.org/0000-0002-4770-8968 \\ $\bowtie$ Corresponding author
}

\section{ABSTRACT}

Small and medium-sized enterprises (SMEs) are vital drivers of China's economy. As in any other country, SMEs in China are exceptionally exposed to the devastating effects of the COVID-19 outbreak. The aim of the paper is to assess the impact of the pandemic on SMEs in China and study the effectiveness of the government's support for SMEs through the crisis. The methodologies applied by the authors included the historical and logical method, the method of the rising from the abstract to the concrete, synthesis, comparative factor analysis, grouping and graphical methods, as well as a systematic and statistical approach. The authors investigate the main policies and initiatives launched in support of smaller businesses and implemented by the People's Bank of China, the Ministry of Finance, the National Development and Reform Commission, the Ministry of Industry and Information Technology, as well as by the two national regulatory authorities - China Banking and Insurance Regulatory Commission and China Securities Regulatory Commission. In this paper the authors analyze the direct and indirect support available to SMEs through financial institutions. The study leads to the conclusions that the state support for SMEs has been effective and helped to avoid a sharp decline in production. However, the spread of the disease in other countries may threaten the recovery of the Chinese economy. Keywords: SMEs; COVID-19; financial institution; anti-crisis policy; guarantee; capital assets

For citation: Jiang M., Hu Y., Li X. Financial support for small and medium-sized enterprises in China amid COVID-19. Finance: Theory and Practice. 2020;24(5):6-14. DOI: 10.26794/2587-5671-2020-24-5-6-14

\section{INTRODUCTION}

The continued spread of coronavirus disease 2019 (COVID-19) has led to delayed resumption of work, traffic control, business closure and restrictions on population movement in many provinces and cities, which have a significant impact on national economic growth in the short term, especially for small and medium-sized enterprises (SMEs) that are strongly associated with economic fluctuations. As an important part of the real economy, SMEs are also an important source of impetus and vitality for the growth of the national economy. Under the impact of the epidemic, the capital flows of SMEs have broken down, and their operational risks have increased sharply. ${ }^{1}$

As an important regulatory tool to boost economic development and maintain social stability, finance

\footnotetext{
${ }^{1}$ Research Group of Ping An Inclusive Finance Research Institute. Do a Good Job in SMEs Financial Services under the Impact of the Epidemic. China Finance. 2020;(5)44-45.
}

can play a key role in risk mitigation for SMEs in crisis management. China's current level of financial development is still low, SMEs need more financial support but difficult to obtain financial funds sufficiently. In line with the principle of serving the real economy and preventing the occurrence of systemic financial risks under the impact of the epidemic, the state has introduced a series of financial assistance policies for SMEs in the form of government intervention "financial rescue". At the same time, the People's Bank of China and the financial regulatory authorities have successively introduced a number of policies to enhance the financial service capacity of financial institutions to achieve the dual objectives of guiding capital flow into the real economy and maintaining financial stability.

This paper will sort out relevant policies issued by the government, understand the purpose and effect of relevant policies, and analyze the future development direction of China's economy under the support 
of various policies. The following arrangements are as follows. First, expound the impact of coronavirus on China's economy, mainly on SMEs. Second, introduce the financial assistance policies provided by the government to SMEs. Third, introduce the financial support policies of the government for financial institutions to prevent the risks of the real economy from being transmitted to the financial system.

\section{THE IMPACT OF THE EPIDEMIC ON THE ECONOMY}

\section{The Impact of the Epidemic on the Macro Economy}

According to the theory of economic growth, the epidemic is not an endogenous factor of economic growth, the decisive factors are labor, capital and technology. But the panic emotion, change of expectation and restriction measures brought by the epidemic will change people's consumption and investment behaviors, thus affecting the macro economy [1]. According to J. Lee and W.J. Mckibbin (2004) [2], the epidemic can affect economic development in three ways. First, the consumption downturn caused by the fear of infection, especially in tourism and retail industry. Second, is to make people feel uncertain about the future economic development through the way of expectation. Third, the epidemic has increased the cost of disease prevention. At present, China's economy is under the attack of unprecedented structural factors (the transformation of old and new drivers of growth, the restructuring of global industrial and value chains) and cyclical factors (the global spread of COVID-19, the collapse of commodity prices and the violent turbulence of financial markets). The impact of COVID-19 will bring great challenges to economic development. ${ }^{2}$

In spite of the change of temporary decisions of consumers and investors caused by epidemic, the driving forces of domestic economic development remain unchanged, and the virtuous circle of economic efficiency improvement, market potential release, consumption and industrial transformation

\footnotetext{
${ }^{2}$ China Economic and Financial Research Group, Bank of China Research Institute. In Response to the Severe Impact of COVID-19, Decisive and Drastic Policy Adjustments are Needed-Bank of China Economic and Financial Outlook Report (Q2 2020). International Finance. 2020;(4):51-59.
}

and upgrading will keep the same. As a result, the domestic economy has not changed in the medium to long term. Some scholars also believe that in the long-run, catastrophic impacts such as the epidemic will bring impetus to the birth of new technologies and the renewal of capital stock, thus improving the long-term total factor productivity [3, 4].Z.Q. Li (2003) [5] takes the SARS as an example, to analyze its influence on the national economy, in the short term the outbreak really has a huge impact on consumption industries, thus bring short-term economic fluctuations. However, in the long-run, the outbreak will induce some formal and informal social changes, and improve the efficiency of resource allocation in the long run, which is conducive to economic growth.

Unlike major natural disasters, COVID-19 does not destroy the material basis of economic production. It reduces or delays short-term demand, but does not harm long-term demand. It severely suppressed the consumption demand, but did not hurt the investment demand. Local impact on the worst-hit areas is large, but the overall impact on the country is limited. According to the preliminary calculation by the National Bureau of Statistics, the GDP of the first quarter of 2020 was 2.0554 trillion yuan due to the epidemic, down $6.8 \%$ year-on-year, of which the value-added of the primary industry was 1018.6 billion yuan, down $3.2 \%$. The value-added of the secondary industry was 7363.8 billion yuan, down 9.6\%. The value-added of the tertiary industry was 12268 billion yuan, down 5.2\%. Since the second quarter, as the spread of the epidemic in China being basically interrupted, the resumption of work and production has been accelerated. Basic industries and important products related to the national economy and people's livelihood have been growing steadily, the basic livelihood of the people has been well protected, and overall economic and social development has been stable. Additionally, the consumption and investment that postpones earlier can have release, national economy can appear compensatory recovery. It can be sure that the impact of the epidemic on China's economy will only be temporary and the fundamentals of China's economy will remain stable and sound [6]. Experience shows that the suppression of consumption and investment by the Ebola virus, Middle East Respiratory syndrome and SARS in 2003 


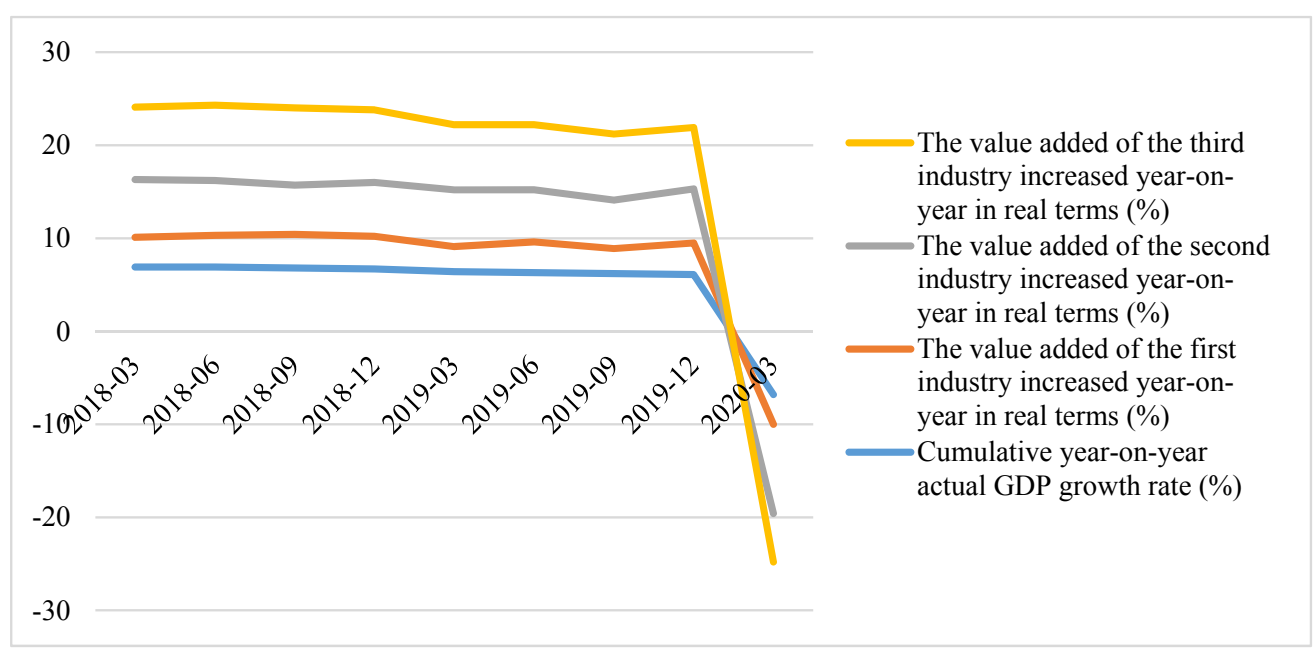

\section{Fig. 1. Quarterly growth rate for GDP and three industries}

Source: compiled by the authors.

is usually temporary, and after the epidemic is effectively controlled, the suppressed economic activities such as consumption and investment quickly rebound, demonstrating the economy's ability to repair itself [7]. However, in the short term, the epidemic will still affect the real economy in four ways [8]. First, due to the spread of the epidemic, the resumption of work after the Spring Festival has been delayed, resulting in the temporary idling of production capacity. Second, the epidemic has led to pessimistic expectations of investors on the economic outlook, lower commodity prices, and weakened the power of enterprises to expand and increase inventories. Third, due to the epidemic, the demand for logistics, catering and other service industries decreased sharply in the short term, and the industrial manufacturing industry was affected through the relevant industrial chain, and the supply side contracted. Fourth, the operation of SMEs is severely damaged, facing a severe survival crisis, and easy to cause employment problems [9] (See Fig. 1).

\section{The Impact of the Epidemic on SMEs}

Although the epidemic will not cause huge losses to China's long-term economic development, it has dealt a near-fatal blow to the development of many SMEs. The survival and resumption of work of SMEs has become "a major priority" in the current economic development [10]. The Business Model Innovation Research Center of Tsinghua University recently conducted a survey for SMEs, and a total of 995 SMEs participated in the questionnaire feedback. According to the survey data, 34\% of enterprises can only last for one month, $17.91 \%$ can last for three months, and only $9.96 \%$ of enterprises can last for more than six months. ${ }^{3}$ SMEs have inherent vulnerability, and their low risk resilience has made them the first to bear the brunt of the epidemic. The investigation conducted by Zhu et al. (2020) during the epidemic period also showed that $85.8 \%$ SMEs had a capital maintenance capacity of less than 3 months. If the enterprises could not receive timely policy support and assistance during the epidemic prevention process, a large number of SMEs would face the risk of bankruptcy [10].

In fact, before the outbreak of the epidemic, the financial chain of SMEs was already under strain due to the double impact of the global economic slowdown and China-USA trade frictions. By the end of 2019 , the accounts receivable balance of private industrial enterprises, represented by SMEs, accounted for $31.3 \%$ of current assets, the highest since data records began, presenting a high liquidity risk [11]. For the sudden outbreak of COVID-19, prevention and control of the flow of people and goods have been tightly restricted both at home and abroad, business's determination to keep factories and workers idle and systemic economic stagnation, impact resistant ability of SMEs. Especially for SMEs in the physical

${ }^{3}$ The data comes from the Report of 995 SMEs jointly investigated by Tsinghua University and Peking University published by China Europe Business Review on February 5, 2020. 
retail, tourism, transportation and logistics industries that have been heavily affected by the epidemic, not only have financial obligations to pay the wages, rent, inventory and cost of loan principal and interest, but also face sales revenue loss, supply chain, and capital chain rupture. Small businesses have been hit hard, facing serious survival crisis. According to the survey data of China Merchants Bank (90.4\% of the interviewed enterprises are SMEs), $24.7 \%$ of the sample enterprises are seriously affected by the epidemic, among which $16.9 \%$ are in trouble and $5.8 \%$ are facing the risk of bankruptcy.

SMEs in China have lots of typical characteristics of "Five-Six-Seven-Eight-Nine". They make more than $50 \%$ of the contribution to the national tax, more than $60 \%$ of GDP, more than $70 \%$ of the technological innovation, more than $80 \%$ of the urban labor employment, and in terms of numbers, small businesses account for 90 percent of the country's businesses. ${ }^{4}$ Therefore, SMEs are the major force of national economic and social development, and an important basis for improving people's livelihood and ensuring employment. To ensure the resumption of work and production of SMEs and tide over the epidemic situation is the prerequisite for the national economy to achieve self-repair. ${ }^{5}$

\section{Financial Support under the Epidemic}

For the financial market, it faces two daunting tasks. First, to give full play to the role of the financial sector in serving the real economy, comprehensively strengthen financial services for epidemic prevention and control, and provide financial support for the development of enterprises under the epidemic. Second, to maintain financial stability, increase the risk tolerance of the financial system, and mitigate the credit risks and even systemic financial risks of financial institutions. The focus and difficulty of "financial rescue" lies in finding a balance between the two tasks, which not only ensures that SMEs can get enough financial support and get out of

\footnotetext{
${ }^{4}$ According to statistics from the State Administration for Market Regulation, by the end of 2019, there were 123 million market players nationwide, among which $38.583,000$ were enterprises and 82.61 million were self-employed.

${ }^{5}$ The source is from the first meeting of the State Council Leading Group for Promoting the Development of SMEs, held on 20 August 2018.
}

trouble smoothly but also maintains the safety of financial institutions and the stability of financial markets and prevents systemic financial risks.

\section{Financial Support Policies for SMEs}

For a long time, China's SMEs have been faced with the problem of difficult and expensive financing. Due to their small scale, poor mortgage ability, and the general problem of information asymmetry, the future development of SMEs has great uncertainty. In order to prevent their own risk and to meet the regulatory requirements, formal financial institutions, dominated by banks, adopt a negative attitude or even credit discrimination towards the financing of SMEs, or raise the financing costs of SMEs by charging high risk compensation. At the same time, due to the imperfect capital market in China and the high financing threshold in the direct financing market, most SMEs are difficult to meet the requirements. Therefore, the financial support needed in the development process of SMEs is either absent or is a mere formality [10]. China's SMEs mainly rely on endogenous financing, and the constraints of their own capital make them easily fall into the development dilemma. It is evident that SMEs in the original macro environment are in urgent need for financial support. Under the impact of the outbreak, SMEs are bound to suffer from liquidity, financing constraints, and the cost of financing and other multiple test and pressure, lead to further deterioration such as its operating conditions, and even lead to business failures. SMEs are in urgent need of financial support with government intervention.

Since the outbreak of COVID-19, the government has given greater priority to supporting the development of the real economy by increasing credit supply, reducing financing costs, and introducing special relief policies to support SMEs and individual businesses, which have given strong support to the prevention and control of the epidemic and the resumption of work and production of SMEs [12]. The cores of the policy are entrenched in two ways. One is to help enterprises to solve the problem of cash flows. The other is to help enterprises to repair credit losses. Among them, the Ministry of Industry and Information Technology issued the Notice on The 
Work related to Coping with the COVID-19 Epidemic to help SMEs to resume work and production and tide over the Difficulties (Notice 14 of MIIT), which includes the financial support for SMEs in a relatively comprehensive way, specifically in the following aspects.

\section{INCREASE CREDIT SUPPORT}

The government is required to urge financial institutions to appropriately reduce loan interest rates, increase credit loans and medium and long-term loans to SMEs that have development prospects but temporarily encounter difficulties due to the epidemic, and refrain from blindly withdrawing, cutting or pressuring loans. If it is difficult to repay the loan at maturity, the loan shall be extended or renewed. In order to solve the information asymmetry problem of SMEs, a new credit investigation model based on multidimensional big data analysis can be promoted to improve the credit score and loan availability of high-quality SMEs. At the same time, we will provide emergency lending support to enterprises that are greatly affected by the epidemic. We will encourage localities where conditions permit to set up loan risk compensation funds and appropriately compensate the non-performing loans granted by financial institutions to SMEs during the epidemic.

\section{Strengthen Financing Guarantee Services}

Under the new normal of the economy, private guarantee companies have a high rate of bad debts and are struggling to survive. At present, it mainly relies on government-backed guarantee companies to solve some financing problems of SMEs (Guo Na, 2013). The government needs to guide governmentmanaged financing guarantee and re-guarantee institutions at all levels to improve their business efficiency and reduce the rates of guarantee and re-guarantee. For those SMEs that are really unable to repay, government financing guarantee institutions at various levels providing financing guarantee services for them should fulfill their obligations of compensation in a timely manner, and appropriately extend the time limit for recovery according to the impact of the epidemic situation. If the debt of SMEs meets the conditions for cancellation, it will be written off and losses will be compensated in accordance with regulations.

\section{Innovate Financing Products and Services}

Actively promote the use of supply chain finance, commercial factoring, accounts receivable pledge, intellectual property pledge and other financing methods to expand the financing supply for SMEs. We should give full play to the convenience and speed of Internet finance, and develop financing products suitable for SMEs during the epidemic as soon as possible to meet their needs. We will give full play to the role of financing service platforms for SMEs across the country, and actively carry out docking among governments, banks and SMEs online. Coordinate with banks and insurance institutions to open the green channel for credit and insurance claim settlement, and speed up lending and claim settlement.

\section{Accelerating Equity Investment and Services}

We will give full play to the synergic effect of national and local development funds for SMEs, encourage private capital to expand equity financing for SMEs, and encourage more investment in innovative and growing SMEs that are temporarily in difficulty due to the epidemic in order to speed up investment. We will guide all kinds of funds to give full play to their platform and resource advantages, increase post-investment services for the companies that are heavily affected by the epidemic, and coordinate various resources such as financing, talent, management and technology, to help them tide over the difficulties.

In China's bank-dominated financial system, the current financial support for enterprises are mainly the credit support from banks. According to a series of preferential credit policies for SMEs issued by China Banking and Insurance Regulatory Commission, including increasing the supply of credit, lower loan interest rates, for overdue loan renewal, etc. under the impact of COVID-19, non-performing loans due to the impact of the epidemic should be exempted from accountability, the government should encourage banks to increase the non-performing loan ratio of SMEs, increase the independent write-off of nonperforming loans, adjust the assessment indicators 
or adjust the assessment weight, and stimulate and increase the enthusiasm of grassroots banks to dare to lend to SMEs. Local governments have also introduced credit enhancement measures to help enterprises lend for the first time and renew loans, and to expand the credit benefits of SMEs. However, credit policies are mainly aimed at enterprises that meet the bank credit conditions, or some enterprises that meet the bank credit conditions after the credit edge and government credit enhancement, which cannot benefit the vast majority of SMEs [15]. Moreover, for a large number of enterprises, the most needed is not debt financing but equity financing: debt financing will increase the cash flow burden of enterprises' debt servicing, worsen their financial strength, which is more vulnerable due to the impact of the epidemic, and increase the risk of financial crisis. Therefore, the Notice 14 of MIIT also stressed the use of equity investment or other innovative financing way to boost the survival and development of SMEs, such as guiding the social capital and all kinds of equity investment fund of SMEs, bank credit, equity investment and loan linkage, developing and perfecting the capital market to guide more capital "blood transfusion” for SMEs (See Table).

\section{Policy Support for Financial Institutions}

At the same time, the epidemic has also had an impact on financial institutions represented by banks, and preventing systemic financial risks is also an issue that regulators attach great importance to [13]. First of all, the COVID-19 outbreak has disrupted the normal operation of banks and other financial institutions, resulting in the postponement of the original business plans of banks. Secondly, the significant impact of COVID-19 on enterprises has affected the normal credit supply of banks, which may lead to potential operational and liquidity risks. What is more noteworthy is that the difficult situation of SMEs affected by the epidemic has made commercial banks, especially SMEs banks, facing serious asset quality risks [14]. On the one hand, the impact of the epidemic has led to the collapse of a large number of SMEs. Although it is conducive to market clearing in the long term, it is very easy to cause credit risks in the banking industry in the short term [15]. On the other hand, SMEs have a high degree of information asymmetry. Driven by continuous policies, the proportion of SMEs' customers in commercial banks keeps rising, which makes post-loan management difficult for Banks and further aggravates credit risks faced by banks.

People's Bank of China, the China Banking and Insurance Regulatory Commission and other financial departments have issued a series of policies that aimed at preventing and controlling the impact of the epidemic on banks to enhance their credit supply and resist risks so as to create a favorable policy environment for financial institutions, strengthen the support for SMEs, and reduce the capital cost of the real economy.

The central bank's policies mainly include. Firstly, carrying out reverse repos to provide sufficient liquidity to the financial market. For example, on February 10,2020, the central bank conducted 900 billion yuan of reverse repos through interest rate bidding. Secondly, targeted RRR cuts will be implemented for SMEs banks with a high proportion of investment in SMEs. In April and May, the Central bank cut the required reserve ratio by 1 percentage point for rural financial institutions and urban commercial banks operating only in provincial administrative regions, releasing about 400 billion yuan of long-term funds, effectively increasing the stable source of funds for banks to serve the real economy and reducing their funding costs. Thirdly, providing accurate support for refinancing and rediscount. In response to the epidemic, the central bank set up 300 billion yuan of special re-loans for epidemic prevention, more than half of which will be invested in SMEs. Subsequently, the central bank extended another 500 billion yuan in new loans and discounts to support the resumption of work and production of SMEs. In April, the central bank continued to increase the refinancing quota of 1 trillion yuan, also giving priority to SMEs. Fourthly, cut the excess deposit reserve ratio. The central bank cut the interest rate on excess reserves that financial institutions hold at the central bank from 0.72 percent to 0.35 percent on April 7, the first cut since 2008, in an effort to guide Banks to park less excess funds at the central bank and use them more to support the real economy. Before the outbreak, China Banking and Insurance Regulatory Commission requirements for commercial banks to set aside the coverage range 


\section{Summary of major credit support policies during COVID-19}

\begin{tabular}{|c|c|c|c|}
\hline Time & Department & Related Policy & Main Content \\
\hline 1 May & $\begin{array}{l}\text { People's Bank of China, Ministry of Finance, } \\
\text { China Banking and Insurance Regulatory } \\
\text { Commission, China Securities Regulatory } \\
\text { Commission, State Administration of } \\
\text { Foreign exchange (SAFE) }\end{array}$ & $\begin{array}{l}\text { Notice on Novel Coronavirus } \\
\text { Pandemic Prevention } \\
\text { and Control with Further } \\
\text { Strengthening Financial } \\
\text { Support }\end{array}$ & $\begin{array}{l}\text { Ensure the total supply of credit, } \\
\text { increase credit support for COVID-19 } \\
\text { prevention and control, and provide } \\
\text { differentiated and preferential financial } \\
\text { services to regions, industries and } \\
\text { enterprises that heavily affected by the } \\
\text { pandemic }\end{array}$ \\
\hline 1 March & $\begin{array}{l}\text { Banking and Insurance Regulatory } \\
\text { Commission, People's Bank of China, } \\
\text { National Development and Reform } \\
\text { Commission, Ministry of Industry and } \\
\text { Information Technology, Ministry of Finance }\end{array}$ & $\begin{array}{l}\text { Notice on Temporary } \\
\text { Extension of Principal and } \\
\text { Interest Repayment for Loans } \\
\text { to SMEs }\end{array}$ & $\begin{array}{l}\text { According to the actual situation } \\
\text { affected by the pandemic, enterprises } \\
\text { are given a certain period of deferred } \\
\text { interest payment arrangement }\end{array}$ \\
\hline 31 March & $\begin{array}{l}\text { Banking and Insurance Regulatory } \\
\text { Commission }\end{array}$ & $\begin{array}{l}\text { Notice on the Promotion } \\
\text { of "Incremental Expansion, } \\
\text { Quality Improvement and } \\
\text { Cost Reduction" of Financial } \\
\text { Services for SMEs in } 2020\end{array}$ & $\begin{array}{l}\text { Make good use of the targeted RRR } \\
\text { reduction policy for inclusive finance, } \\
\text { reasonably determine the loan interest } \\
\text { rates for SMEs, and reduce the overall } \\
\text { financing costs of loans to SMEs }\end{array}$ \\
\hline 7 April & $\begin{array}{l}\text { Banking and Insurance Regulatory } \\
\text { Commission }\end{array}$ & $\begin{array}{l}\text { Notice on Make Full Use } \\
\text { of the Role of "Banking- } \\
\text { Taxation Interaction" to Help } \\
\text { SMEs Resume Work and } \\
\text { Production }\end{array}$ & $\begin{array}{l}\text { In view of the more urgent financial } \\
\text { needs of SMEs during the pandemic, } \\
\text { increase support for tax credits and loans } \\
\text { to help enterprises to resume work and } \\
\text { production and overcome the difficulties }\end{array}$ \\
\hline 1 June & $\begin{array}{l}\text { People's Bank of China, Banking and } \\
\text { Insurance Regulatory Commission, Ministry } \\
\text { of Finance, National Development and } \\
\text { Reform Commission, Ministry of Industry } \\
\text { and Information Technology }\end{array}$ & $\begin{array}{l}\text { Notice on Further } \\
\text { Implementation of Periodic } \\
\text { Deferred Repayment of } \\
\text { Principal and Interest on } \\
\text { Loans to SMEs }\end{array}$ & $\begin{array}{l}\text { For inclusive SMEs loans, the } \\
\text { commercial loans can be postponed, } \\
\text { banking financial institutions should } \\
\text { provide support with repayment } \\
\text { convenience }\end{array}$ \\
\hline
\end{tabular}

Source: compiled by the authors.

of $120 \%$ to $150 \%$, on April 21,2020 , state council executive meeting decided to SMEs banks set aside coverage regulatory requirements stage by $20 \%$, adjusted to $100 \% 130 \%$. Without considering the bad loan balance changes, in theory, the biggest one can release 300 billion yuan in loans impairment provision, improve the ability of SMEs bank credit. As it can be seen from the above policies, People's Bank of China and the financial regulatory authorities are committed to helping SMEs banks tide over the epidemic, while improving their ability to support SMEs, so as to achieve the dual goals of ultimately promoting the flow of funds to the real economy and maintaining the stability of the financial system (See Fig. 2).

\section{CONCLUSION AND OUTLOOK}

COVID-19 has had a severe impact on SMEs and financial markets. As the supporting force of China's economic development, the survival and recovery of SMEs are crucial to the future development of China's economy. To support the development of SMEs and maintain the stability of the financial market, the government has issued a number of financial support policies. Under the influence of various policies of the government and financial regulatory authorities, the macro-economy gradually stabilized, the resumption of work and production of SMEs entered the right track, and the overall stability of the financial market was achieved. ${ }^{6}$

Although the epidemic in China has been effectively brought under control, as the pandemic continues to spread internationally, the downside risks to

${ }^{6}$ China Economic and Financial Research Group, Bank of China Research Institute. In Response to the Severe Impact of COVID-19, Decisive and Drastic Policy Adjustments are Needed-Bank of China Economic and Financial Outlook Report (Q2 2020). International Finance. 2020;(4):51-59. 


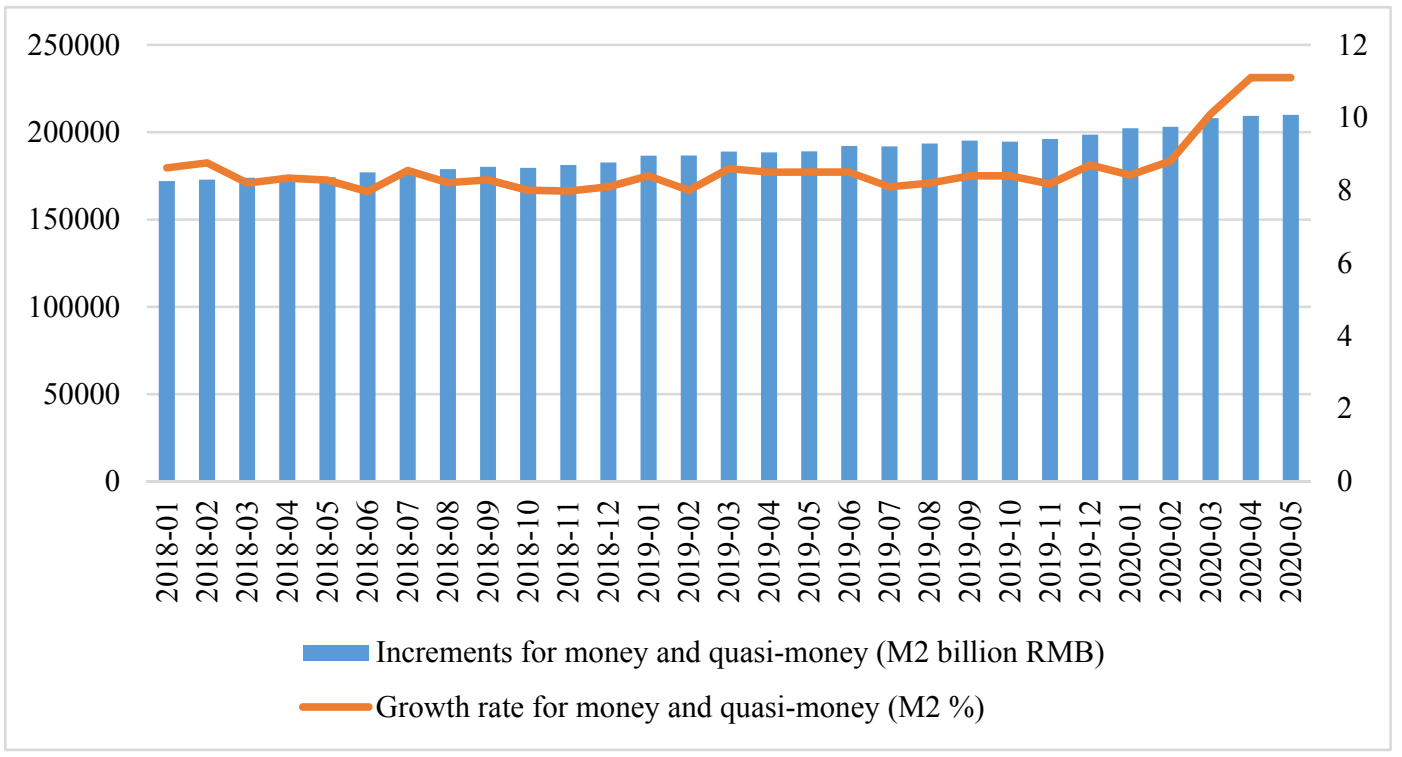

Fig. 2. Increments and growth rate for money and quasi-money (M2), monthly figures

Source: compiled by the authors.

the world economy have intensified and destabilizing and uncertain factors have significantly increased. As a result, enterprises will face new difficulties and challenges in resuming work and production as well as economic and social development [16]. Data from the General Administration of Customs showed that in the first quarter of 2020, the total import and export value of China's goods trade was 6.57 trillion yuan, down 6.4 percent compared with the same period last year, among which exports were 3336.3 billion yuan, down 11.4 percent year-on-year. Export is one of the three engines driving China's economic development. The contraction of overseas market demand will cause a new round of impact on foreign trade enterprises and economic development. Since a large proportion of foreign trade enterprises are SMEs, the out-of-control epidemic abroad will make the resumption of work and production of SMEs even worse. At present, the state is supporting the development of SMEs foreign trade enterprises by developing cross-border e-commerce, guiding the transfer of export products to domestic market, expanding diversified international market, and encouraging foreign trade innovation. At the same time, the state is guiding financial institutions to provide financing support and insurance services to try their best to rescue SMEs foreign trade enterprises. However, if the pandemic triggers a sustained global recession, the future course of economic recovery and development will be uncertain.

\section{REFERENCES}

1. He C.Y., Wen Y.C., Chang Y.L. Novel coronavirus pneumonia epidemic to measure the impact of China's economy. Quantitative Economic and Technical Economic Research. 2020;37(5):3-22. (In Chinese).

2. Lee J., Mckibbin W.J. Globalization and disease: The case of SARS. Asian Economic Papers. 2004;3(1):113-131. DOI: $10.1162 / 1535351041747932$

3. Skidmore M., Toya H. Do natural disasters promote long-run growth? Economic Inquiry. 2002;40(4):664-687. DOI: 10.1093/ei/40.4.664

4. Lou F.P. Economic and financial impact of epidemic situation of COVID-19 and suggestions for response-analysis from the perspective of infectious disease. Southern East Finance. 2020;(4):34-43. (In Chinese).

5. Li Z.Q. Short-term and long-term analysis of the impact of SARS on national economy. Economics Science. 2003;(3):25-31. (In Chinese).

6. Yang S.P., Zhang X.H. Impact of COVID-19 on credit operations and response measures. Agricultural Development and Finance. 2020;(3):54-56. (In Chinese). 
7. Zhou M.H. A look at the economic impact of the COVID-19 epidemic. Financial Market Research. 2020;(3):19-26. (In Chinese).

8. Huang J.H., Wang J.W. Analysis of impact of the COVID-19 epidemic on China's economy and finance. Banker. 2020;(3):29-31. (In Chinese).

9. Zhang Z.Y., Ma Y.F., Hu X.C. Research on financial supply support for SMEs under the impact of the epidemic. Fiscal Research. 2020;(4):58-65. (In Chinese).

10. Zhu W.X., Zhang P., Li P.F., Wang Z. Firm crisis, government support and policy efficiency under the epidemic shock: Evidence from two waves of questionnaire on SMEs. Management World. 2020;(4):13-26. (In Chinese).

11. Zhao H., Song X.J. Risk and countermeasures of Pratt \& Whitney financial under the influence of COVID-19. Banker. 2020;(4):11-13. (In Chinese).

12. Wu T.T., Zhu A.A. The impact of COVID-19 on China's economy and countermeasures. South Finance. 2020(5):3-11. (In Chinese).

13. People's Bank of China, Yichang Central Sub-branch research group, Peng Q.C. Analysis of the impact of COVID-19 on the banking sector - based on a survey in Yichang, Hubei Province. WuHan Finance. 2020;(3):85-88. (In Chinese).

14. Wu Z.Y., Zhu H.M., Zhu J.S. Impact of COVID-19 on financial system and policy suggestions. The Economics Aspects. 2020;(3):1-6. (In Chinese).

15. Song Q.H., Tong S.Q. The impact of COVID-19 on China's SMEs banks and countermeasures. Financial Supervision. 2020;(10):10-17. (In Chinese).

16. Wang Y. Precise implementation of the financial support and stable foreign trade policy. China Finance. 2020;(10):3435. (In Chinese).

\section{ABOUT THE AUTHORS}

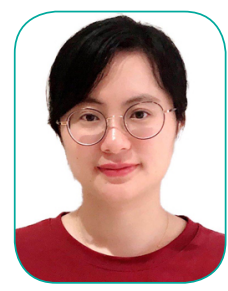

Min Jiang - doctoral student, Shanghai University of Finance and Economics, Shanghai, China jamie891115@163.com

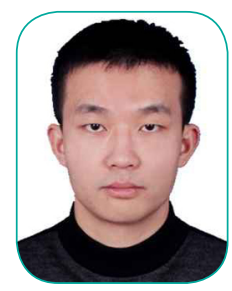

Yuanhong $\mathbf{H u}$ - doctoral student, Shanghai University of Finance and Economics, Shanghai, China feimahong90@163.com

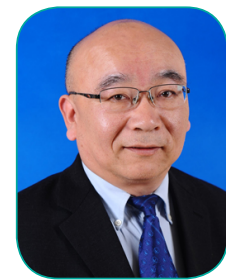

Xin $\boldsymbol{L I}$ - Dr. Sci. (Econ.), Prof., Director, Institute of Eurasian Studies, National Center for SCO - Shanghai University of Political Science and Law, Shanghai, China rusland@126.com

\section{Authors' declared contribution:}

Min Jiang - summary of results and conclusions.

Yuanhong $\mathbf{H u}$ - compilation of statistics, tabular and graphical presentation of results, research findings.

Xin Li - articulation of issue, article concept development, critical analysis of the literature.

The article was submitted on 20.07.2020; revised on 30.07.2020 and accepted for publication on 04.08.2020. The authors read and approved the final version of the manuscript. 